\title{
A hybrid life cycle assessment based fuzzy multi-criteria decision making approach for evaluation and selection of an appropriate municipal wastewater treatment technology
}

\author{
Sheetal Jaisingh Kamble ${ }^{1}$ Anju Singh ${ }^{1} \cdot$ Manoj Govind Kharat ${ }^{1}$
}

Received: 19 April 2016/ Accepted: 11 March 2017/Published online: 28 March 2017

(C) Springer International Publishing Switzerland 2017

\begin{abstract}
Multiple-criteria decision-making (MCDM) has become a main area of research for dealing with complex environmental decision-making problems. In this paper, a hybrid life cycle assessment (LCA) based fuzzy MCDM methodology is developed for the evaluation and selection of appropriate municipal wastewater treatment (WTT) technology based on expert opinion and questionnaires. Further, the study also aims to identify the key evaluation criteria in the process of selecting WTT from a sustainability perspective. The use of fuzzy MCDM in wastewater management has the advantage of rendering subjective and implicit decision-making more objective and analytical, with its ability to accommodate both qualitative and quantitative data. This study provides a systematic approach towards WWT technology selection, in which four-phase procedure is proposed. First, the appropriate technology evaluation and selection criteria were derived from the literature, LCA and experts' opinion. Next, in the second stage, the fuzzy Delphi method was used to evaluate and screen the critical factors for the evaluation of technology alternatives by interviewing the experts. Twelve criteria including sustainability and those derived from LCA and life cycle costing were obtained consisting of both qualitative and quantitative criteria. In the third stage, the weights of the selection criteria as the measurable indices of the WWT technologies were determined by fuzzy pairwise comparison matrices of analytic hierarchy
\end{abstract}

Manoj Govind Kharat

manojgkharat@gmail.com

Sheetal Jaisingh Kamble

sheetaljkamble@gmail.com

1 National Institute of Industrial Engineering (NITIE), Powai, Mumbai, Maharashtra 400087, India process. Finally, the fuzzy the technique for order of preference by similarity to ideal solution technique was used for ranking the alternatives. The six most commonly used WWT technologies, viz. sequencing batch reactors (SBR), membrane bioreactor (MBR), moving bed bio-film reactor (MBBR), soil biotechnology, facultative aerated lagoon and activated sludge process were evaluated. The present study is the first study of its kind to develop a hybrid LCA-based fuzzy MCDM methodology for the selection of best WWT alternatives. Results illustrated that advanced technologies, MBR, SBR and MBBR are the preferred options with MBR the most preferred one followed by SBR and MBBR. The developed technology assessment framework enables decision makers to understand the complete evaluation and selection process better and provide a more accurate, effective, and systematic decision support framework. The framework is superior to existing methods since it has the capability of representing vague qualitative data and presenting all possible results with different degrees of membership. The framework developed and applied in this work will help identify appropriate WWT technologies for various decision-making situations faced while managing wastewaters.

Keywords Wastewater treatment - Technology selection . Sustainability $\cdot$ Multi-criteria decision-making $\cdot$ Life cycle assessment · Fuzzy logic · Fuzzy Delphi · Fuzzy AHP . Fuzzy TOPSIS

\section{Introduction}

Environmental decision-making is multidimensional in nature and requires the participation of multiple stakeholders (Balasubramaniam and Voulvoulis 2005; 
Avramenko et al. 2010; De Feo et al. 2014; MolinosSenante et al. 2016). Often, the rational decision-making process is hindered considering the difficulty in collating and analysing all the relevant data. Wastewater treatment (WWT) and management are one of the major environmental concern worldwide in developing economies (Kalbar et al. 2015; Dursan 2016a, b). The WWT faces many challenges such as increasing energy costs, removal of pollutants and trace organics, depletion of resources, growing demand for water conservation as well as more stringent regulations (Reardon et al. 2013; Tan et al. 2014; Kalbar et al. 2016). The appropriate treatment of wastewater and further its reuse can help to solve issues mentioned above and the problem of water scarcity saving valuable resources along with a reduction in the use of freshwater and the negative environmental impacts caused by improper treatment of wastewater (Garcia and Pargament 2015; Kalbar et al. 2016). As a result, wastewater is now being considered more as a resource than as a waste with the recovery possibilities for clean water, energy and various resources satisfied by novel approaches and emerging technological developments (McCarty et al. 2011; Zayed et al. 2015). However, the appropriate treatment of wastewater depends upon the selection of appropriate technology (Kalbar et al. 2012a, b, 2013; Bozkurt et al. 2016; Dursan 2016a). It is now well recognised that the implementation of the technological options that balance the technological possibilities with the priorities of the community would help to realise the aim of "sustainable development". (i.e. stakeholder satisfaction: Asolekar et al. 2014).

WWT technology evaluation and selection is a multistage, multi-criteria complex decision-making process, ranging from evaluating and obtaining criteria, valuation of those criteria to comparing the technological alternatives based on those criteria (Ibáñez-Forés et al. 2014; Kalbar et al. 2016; Molinos-Senante et al. 2016). The involvement of multiple conflicting factors such as cost, land use, reliability, and flexibility in the decision-making process, thus, makes the selection of WWT technology an MCDM problem (Ilangkumaran et al. 2013; Molinos-Senante et al. 2014). This issue is further aggravated due to the availability of several innovative WWT technological alternatives presenting a prominent challenge to decision analysts and policy makers in the domain of WWT and management (Kalbar et al. 2012a, b). MCDM techniques are very useful to deal with such complex decision-making problems, as they use a structured and logical approach to model the problems (Avramenko et al. 2010; Kalbar et al. 2012a, b; Molinos-Senante et al. 2014; Dursan 2016a, b). Hence, it is necessary to develop a MCDM framework that provide the rationale behind selecting the appropriate technology incorporating sustainability indicators and decisive factors such as LCA and LCC that are suitable for use in the context of a growing economy and increasing burdens on existing environmental resources (Bani et al. 2009; Hamouda et al. 2009; Garrido-Baserba et al. 2015).

Often, the multi-criteria, multi-alternative decisionmaking processes are associated with uncertain, incomplete and imprecise information accompanied by the vagueness of human feeling and recognition. The decision maker preferences are often expressed in linguistic terms (e.g. "very low", "low", "medium", "high", or "very high") (Wang et al. 2009). These conditions make it is difficult to quantify and provide exact numerical values for the criteria conveying the exact feeling and recognition made by the decision makers. Therefore, most of the selection parameters cannot be given precisely (Ekmekçioğlu et al. 2010). This transition from vagueness provided by linguistic values to numeric quantification can be resolved by employing fuzzy set theory (Pochampally et al. 2003; Avramenko et al. 2010; Liu et al. 2012; Tan et al. 2014; Cintula et al. 2015). Hence, taking into account the above consideration the current study attempts to use fuzzy MCDM methods like fuzzy Delphi method (FDM), fuzzy analytic hierarchy process (FAHP) and fuzzy the technique for order of preference by similarity to the ideal solution (FTOPSIS) for appropriate WWT technology evaluation and selection.

In the present study, a hybrid LCA-based fuzzy MCDM decision-support framework for selection of appropriate WWT technologies is developed. The study aims at providing practitioners with a ready-to-use model for appropriate WWT technology selection. Sustainability indicators and indicators derived from LCA and LCC are utilised for the evaluation and selection process. To accomplish that, first, the appropriate technology assessment and selection criteria are derived from the literature, LCA and experts opinion. Next, in the second stage, the FDM is used to evaluate and screen the critical factors for the evaluation of technology alternatives by interviewing the foregoing experts. In the third stage, the weights of the selection criteria as the measurable indices of the WWT technologies are determined by FAHP. Finally, the FTOPSIS technique is used for ranking the alternatives. The contribution of this work is the application of reliable methods to the problem of the WWT technology selection and the development of a comprehensive procedure to solve this issue.

The remainder of the paper is organised as follows: "Introduction" presents the WWT technology selection problem and highlights the need for MCDM tools. In "Literature review", a brief literature review of previous studies is presented with a focus on WWT technology selection-related problem and application of MCDM techniques. The "Materials and methods" section presents a short description of the techniques applied in the current study with their brief procedures. The results of the 
analysis are discussed in "Results and discussion", and finally, the conclusions are outlined in "Conclusion" with suggestions for future research.

\section{Literature review}

The research contribution of MCDM techniques in WWT has been gradually increasing since the 1990s (De Felice and Petrillo 2013). Since then, several attempts have been made to address WWT technology selection problems using various MCDM methods (Tecle et al. 1988; Tecle and Duckstein 1990; Tang and Ellis 1994; Zeng et al. 2007; Kalbar et al. 2013, 2015). In the field of WWT, Tecle et al. (1988) were the first to apply MCDM approach to the selection of WWT alternatives. The study made use of three MCDM methods, namely, compromise programming (CP), cooperative game theory (CGT) and ELimination Et Choix Traduisant la REalité (ELECTRE-I, i.e. ELimination and Choice Expressing REality) for the analysis. Ten criteria were used for evaluation, and all the three methods identified the same alternative as the best alternative. $\mathrm{Li}$ and Guangwen (1990) selected best WWT alternatives to control river water pollution using multi-objective programming method and AHP technique.

Balkema et al. (2001) developed a methodology comparing WWT systems for assessing sustainability. Integer programming (having the objective function as a weighted sum of the sustainability indicators) was used to select best WWT options. Zeng et al. (2007) combined AHP with grey relational analysis (GRA) technique for the optimal selection of WWT alternatives. Anagnostopoulos et al. (2007) applied FAHP for the selection of the best WWT process. Khoram et al. (2007) also highlighted that FAHP technique would be applicable for prioritising the methods of reusing the treated wastewater and would also be related to ranking the strategies. Similarly, Karimi et al. (2011) have reported an FAHP approach for selection of WWT technology. The study considered several criteria encompassing technical, economic and environmental for the purpose of evaluation. Gomez-Lopez et al. (2009) used the TOPSIS technique select the best WWT technology for disinfection of treated wastewater. Garrido-Baserba et al. (2010) developed a complex decision support system (DSS) based on knowledge base for selecting WWT alternative considering 88 factors. Similar to Zeng et al. (2007), Pophali et al. (2011) used AHP in combination with GRA to select the most suitable WWT option. Bottero et al. (2011) applied AHP and the analytic network process (ANP) for the comparative assessment of different WWT systems. The results obtained from both the models were compared to determine best WWT option.
Ilangkumaran et al. (2013) applied hybrid MCDM methods comprising FAHP, preference ranking organization method for enrichment of evaluations (PROMETHEE) and GRA techniques to optimise WWT technology selection. Prasad and Tembhurkar (2013) developed an AHP based software for the selection of best WWT alternative. 14 relevant factors and 13 subfactors were identified for the selection analysis. The model helped to reduce the margin of errors during optimisation due to a number of parameters in the hierarchy levels. Sadr et al. (2013) applied multicriteria analysis (MCA) technique for systematic appraisal and selection of wastewater reuse technologies under various scenarios. The multi-criteria analysis based ranking of candidate technologies provided a relative indication of the suitability of various wastewater reuse technologies. Molinos-Senante et al. (2014) applied AHP to determine the weights to a set of criteria to incorporate the expert's preferences in the assessment of the sustainability of WWT alternatives. Curiel-Esparza et al. (2014) combined AHP, Delphi method and VIseKriterijumska Optimizacija i kompromisno Resenje (VIKOR) approach for evaluating five disinfection alternatives in wastewater reuse projects. Tan et al. (2014) proposed a fuzzy AHP based framework for the evaluation of different municipal WTT plants. However, in most of these studies, the source of information for choosing criteria and indicators was the secondary data from the literature review. Since the decision making should be based on specific local constraints and capacities, it is necessary to gather local experts' opinions. Further, the studies mentioned above fail to address the uncertainty of information and the vagueness of human feeling and recognition. Therefore, the current study employs fuzzy techniques to deal with this issue. Thus, it provides a more robust and flexible framework, which makes it possible to satisfactorily redress many of the difficulties arising from a lack of precision.

Kalbar et al. (2012a, b, 2013, 2015) applied AHP and TOPSIS for optimal selection of WWT technologies. The studies employed a scenario-based approach to decision making in which four technologies were evaluated and compared against various criteria. Hadipour et al. (2015) employed AHP technique to identify and select the best WWT option in Iran. Molinos-Senante et al. (2015) applied ANP to rank a set of seven WWT technology systems for secondary treatment in small communities. Gao et al. (2015) developed a method with attribute aspiration (e.g. cost, benefit) for the selection of WWT technologies. For each type of attribute aspiration, the calculation formula of utility values of alternative concerning attributes was given. Then, using the calculation formulae, the attribute values were transformed into the corresponding utility values. Finally, the overall ranking value of each alternative was calculated determining the ranking order of 
options. Ouyang et al. (2015) developed an integrated approach combining FAHP and multidimensional scaling (MDS) in the selection of five natural WWT alternatives. FAHP was used to determine the weights of the criteria followed by the application of MDS method to determine the optimal alternative directly through the coordinates associated with each alternative in a two-dimensional configuration. Zayed et al. (2015) applied AHP with the multi-attribute utility theory to develop a performance rating and efficiency model for the WWT plants. Bozkurt et al. (2016) used mixed integer (non) linear programming (MI (N) LP) for best WWT process selection comparing their optimality. More recently, Rawal and Duggal (2016) developed and applied an LCC based assessment approach for selecting the appropriate WWT technology. Quantitative weights from the LCC were used to compare alternative systems with similar outcomes in addressing the system's objective, having different cost structures, reliability and effluent quality. Kalbar et al. (2016) developed MCDM based framework for evaluating and selecting appropriate WWT technology taking into account different scenarios. However, the study did not consider the uncertainty involved in the decision-making process. Dursun (2016a) applied fuzzy VIKOR technique to identify the most suitable WWT alternative, but lack the consideration of sustainability indicators in the evaluation and selection process. Similarly, Dursun (2016b) proposed a fuzzy MCDM approach based on 2-tuple fuzzy linguistic representation model, decision making trial and evaluation laboratory (DEMATEL) method and fuzzy TOPSIS method to evaluate and rank most appropriate WWT alternative. Molinos-Senante et al. (2016) estimated the eco-efficiency of a sample of real wastewater treatment plants. The developed model was allowed to calculate an inefficiency score for each variable (cost factors, pollutant removal and greenhouse gases) involved in the model. Ehrampoush et al. (2016) employed AHP for choosing the best dye removal technique in textile WWT. Aydiner et al. (2016) applied AHP for analysing the preferability of four innovative dual membrane combinations and a traditional system for dairy WWT and management. Hu et al. (2016) evaluated the WWT levels for enterprises employing fuzzy AHP approach.

The studies in the literature show that efforts have been made to address the problem of WWT alternative selection using MCDM approach; however, the complete information available to the decision maker is not utilised in the decision-making process. The models applied suffer from the drawback that some the criteria cannot be expressed numerically, and therefore cannot be accurately accounted for in these models. Additionally, sustainability indicators and attributes derived from LCA and LCC have not been used in any of these studies. Thus, the current study incorporates the essential sustainability criteria in the fuzzy MCDM process while selecting WWT technology.

Even though AHP is widely used in many decisionmaking problems, it owns some limitations (Mikhailov 2003; Chan 2003). The conventional AHP cannot reflect the rational thinking style. Moreover, there are very few studies in the literature that took into account the uncertainty involved in the decision-making process and have applied fuzzy logic to select WWT technologies. Thus, to deal with the vagueness of human thought and recognition, the fuzzy set theory (Zadeh 1965) is introduced in the current study to express the linguistic terms in the decisionmaking process. The present study is the first study of its kind to develop a hybrid LCA-based fuzzy MCDM model for selection of best WWT alternatives.

Till date, the main environmental concern of WWT was the water quality of final discharge or reusable wastewater. However, the current study aims to incorporate the environmental criteria in the decision-making process by applying a hybrid LCA and fuzzy MCDM approach considering specific wastewater management scenario. The present study embeds the environmental life cycle thinking approach in making decisions and presents its application to a set of WWT plants. It provides significant insight into the preferences of WWT criteria in the decision-making process with a simple, robust and flexible methodology to evaluate and select the most suitable WWT technology of a wide set of possibilities.

The research work focused on studying only the operation and maintenance (O\&M) phase of the urban municipal WWT plants considering the social, economic, environmental and legal aspects. The evaluation and selection criteria derived from the stepwise procedure represented the aspects mentioned above adequately, covering factors such as wastewater characteristics, disposal standards, and population size, thereby leading to a holistic approach. Further, due to the unavailability of quantitative data on environmental and human health toxicity factors, the study considered only limited part of these factors.

\section{Materials and methods}

WWT technology selection is a complex and multidisciplinary problem that should be addressed taking into consideration the environmental, social, technical as well as economic aspects. The evaluation and selection criteria must cover the dimensions mentioned above of sustainability. Though it can be observed an increasing tendency in considering social aspects such as the creation of employment or social acceptability, environmental and economic criteria as atmospheric emissions, energetic balances and internal costs are the most preferred to assess 
and select technologies. However, the selection of criteria is recommended to be done by the decision maker, who must choose the criteria based on his/her opinion.

The current study evaluated six alternative WWT technologies using 12 relevant criteria and established a methodology that aids decision makers in assessing the prioritisation of the WWT technologies. On the basis of current practices, wide application and considering the future objectives, the alternative WWT technologies considered were, sequencing batch reactor (SBR), membrane bioreactor (MBR), moving bed bio-film reactor (MBBR), facultative aerated lagoons (FAL), soil biotechnology (SBT) and conventional activated sludge process (ASP).

\section{Identification and screening of the evaluation and selection criteria}

In evaluating and selecting WWT technologies, judicial choice of criteria is essential. The inclusion of multiple criteria in the assessment increases complexity and requires more data and hence more time and cost. Further, the selected criteria should also characterise all the aspects of the technologies to be evaluated. A range of economic and environmental quality indicators have been used for decades to assess the WWT systems. Nevertheless, during the last 20 years, there has been an increasingly intense desire of integrating the concept of sustainability in the assessment of WWT technologies (Molinos-Senante et al. 2014). In the current study, care is taken to address this issue.

\section{Fuzzy Delphi method}

Conventional Delphi method is costly and more timeconsuming, as it needs repetitive surveys to allow values to converge (Hwang and Lin 1987; Ishikawa et al. 1993). Furthermore, the experts' judgments cannot be adequately reflected in quantitative terms, due to the differences in the meanings and interpretations of their opinions resulting in vagueness. Hence, to avoid this and for proper quantification of linguistic terms, the concept of combining fuzzy set theory and Delphi method was proposed by Murray et al. (1985) naming it the fuzzy Delphi method (FDM) which was later developed by Ishikawa et al. (1993). In the group decision-making approach, applying FDM, the fuzziness of common understanding of experts could be solved and evaluated on a more flexible scale (Ishikawa et al. 1993; Noorderhaben 1995). With the application of FDM, the efficiency and quality of questionnaires could be improved reducing the uncertainty, cost and time. The current research study used FDM for the screening of alternate factors solving the group decision uncertainty problem. The triangular membership functions and the fuzzy set theory was utilised for the screening and evaluation purpose. Thus, more objective assessment and selection factors could be screened through the statistical results.

An initial questionnaire was designed and pre-tested with the help of academic experts (2) and consultants (1). Further, by expert's opinion, the questionnaire was validated, and final questionnaire was prepared. Finally, after determining the objectives preliminary as environmental, social, technical, economic, employment and resource recovery, 17 evaluation criteria based on relevant literature, sustainability aspects, attributes derived from LCA and LCC were determined. To enable the incorporation of the 'sustainability' aspect into the decision-making process, the indicators acceptability, public participation, replicability and indicators quantifying the robustness of the system were incorporated into the analysis. Next, the FDM procedure was applied to screen the most important and relevant criteria.

The FDM steps are as follows:

1. Collection of opinions of decision group: a team of nine experts from the academic and research domain, government agencies and consulting WWT companies was formed for quantifying the qualitative criteria. This approach is in agreement with the recommendation of earlier studies (Hsu et al. 2010; Kardaras et al. 2013). The 17 criteria as the key evaluation factors of WWT technology were determined, and an FDM interview table was set up. Next, the evaluation score of each alternate factor's significance given by each expert using linguistic variables in questionnaires was obtained.

2. Setting up triangular fuzzy numbers: This step involved the calculation of the evaluation value of the triangular fuzzy number of each alternate factor given by experts and the determination of the significant triangular fuzzy number of the alternate factor. This study used the geometric mean model of the mean general model proposed by Klir and Yuan (1995) for FDM to find out the common understanding of group decision. The fuzzy numbers used for this purpose with their definitions are shown in Table 1. The fuzzy scale utilised for the evaluation is shown in Fig. 1. The computing formula is illustrated as follows:

If the evaluation value of the significance of no. $j$ element given by no. $i$ expert of $n$ experts is $\tilde{w}_{i j}=\left(a_{i j} ; b_{i j} ; c_{i j}\right), i=1,2 ; \ldots ; n ; j=1,2 ; \ldots, m$. Then the fuzzy weighting $\tilde{w}_{j}$ of no. $j$ element is given by, $\tilde{w}_{j}=\left(a_{j} ; b_{j} ; c_{j}\right) ; j=1,2 ; \ldots, \mathrm{m}$. 
Table 1 Definitions of fuzzy number

\begin{tabular}{lll}
\hline \multicolumn{2}{l}{ Fuzzy numbers } & Definition \\
\hline$\tilde{1}$ & $(1,1,1)$ & Equally important \\
$\tilde{2}$ & $(1,2,3)$ & Equally to moderate important \\
$\tilde{3}$ & $(2,3,4)$ & Moderately more important \\
$\tilde{4}$ & $(3,4,5)$ & Moderately and strongly important \\
$\tilde{5}$ & $(4,5,6)$ & More strongly important \\
$\tilde{6}$ & $(5,6,7)$ & Strongly and very strongly important \\
$\tilde{7}$ & $(6,7,8)$ & More very strongly important \\
$\tilde{8}$ & $(7,8,9)$ & Very strongly to extremely important \\
$\tilde{9}$ & $(8,9,9)$ & Extremely more important \\
\hline
\end{tabular}

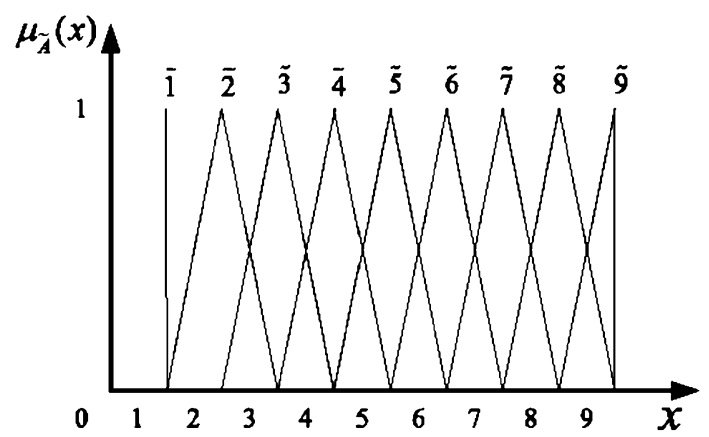

Fig. 1 The fuzzy numbers scale used

Among which

$a=\operatorname{Max}_{i} a_{i j}, b_{j}=1 / n \sum_{(n-1)}^{n} b_{i j}, c=\operatorname{Max}_{i} C_{i j}$

3. Defuzzification: using the simple centre of gravity method the defuzzification of the fuzzy weight $w_{j}$ of each alternate element to absolute value $S_{j}$, was obtained as follows:

$S_{j}=a_{j}+b_{j}+c_{j} / 3$ where $j=1,2, \ldots, m$

4. Screening evaluation indexes: finally proper factors can be screened out from numerous factors by setting the threshold alpha $(\alpha)$. The general FDM diagram with threshold $\alpha$ is shown in Fig. 2. The principle of screening is as follows:

If $S_{j} \geq \alpha$, then no. $j$ factor is the evaluation index.

If $S_{j}<\alpha$, then delete no. $j$ factor.

All criteria with $\alpha$ value less than eight were deleted. Thus, 5 out of 17 primary criteria were deleted, retaining 12 criteria. The output of FDM is shown in Table 2. The important evaluation criteria, after screening with their operational definitions, are listed in Table 3. Thus, more objective evaluation criteria could be obtained.

Based on the FDM, a consensus among the experts was achieved which was used to establish a hierarchical structure. Thus, the WWT technologies were evaluated and

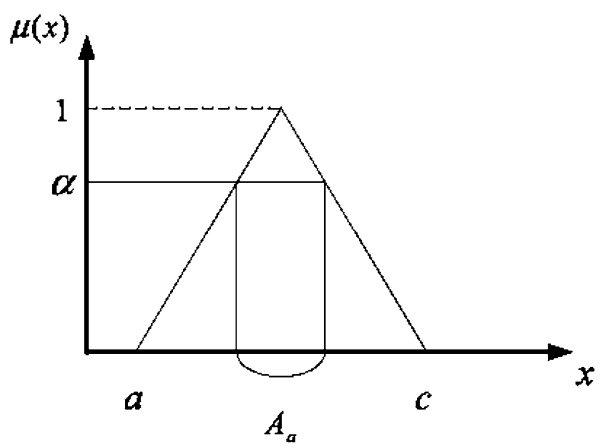

Fig. 2 Fuzzy Delphi method diagram

selected based on the 12 screened criteria. The criteria identification, screening process and technology assessment and selection framework is presented in Fig. 3.

In the current research, the two criteria global warming potential (GWP) and eutrophication potential (EP) were estimated and confirmed by carrying out LCA of WWT technologies. The next criterion was derived from LCC estimated as NPW representing the capital cost and O\&M cost of the plant. The capital costs include the cost incurred for civil works, electromechanical equipment and cost of land. O\&M costs include electrical energy and chemicals costs required to operate the plant, labour costs, spares and maintenance costs. The resource recovery, land requirement (in $\mathrm{m}^{2}$ ) and the number of workforce requirement for operation of the plant criteria represent the constraint from the resources point of view. Thus, a balanced set of criteria obtained from FDM that provides a holistic assessment was chosen for evaluating the experts' preferences towards appropriate sustainable WWT technologies.

\section{Calculating the weights of evaluation criteria}

In the context of WWT technology selection, the priority or weights assigned to the criteria plays a vital role in obtaining results and must be applied with care, since the final decision can vary significantly depending on the importance assigned to each criterion (Gaudreault et al. 2009; Pilavachi et al. 2009). To achieve this, the current study applied FAHP.

\section{Fuzzy analytic hierarchical process}

The linguistic scale of traditional analytic hierarchy process (AHP) method could not express the fuzzy uncertainty when a decision maker is making a decision. Therefore, Laarhoven and Pedrycz (1983) proposed the FAHP, which is the combination of AHP and fuzzy theory. In this study, fuzzy logic was combined and used along with AHP, which resulted in a Fuzzy-AHP methodology for reviewing and 


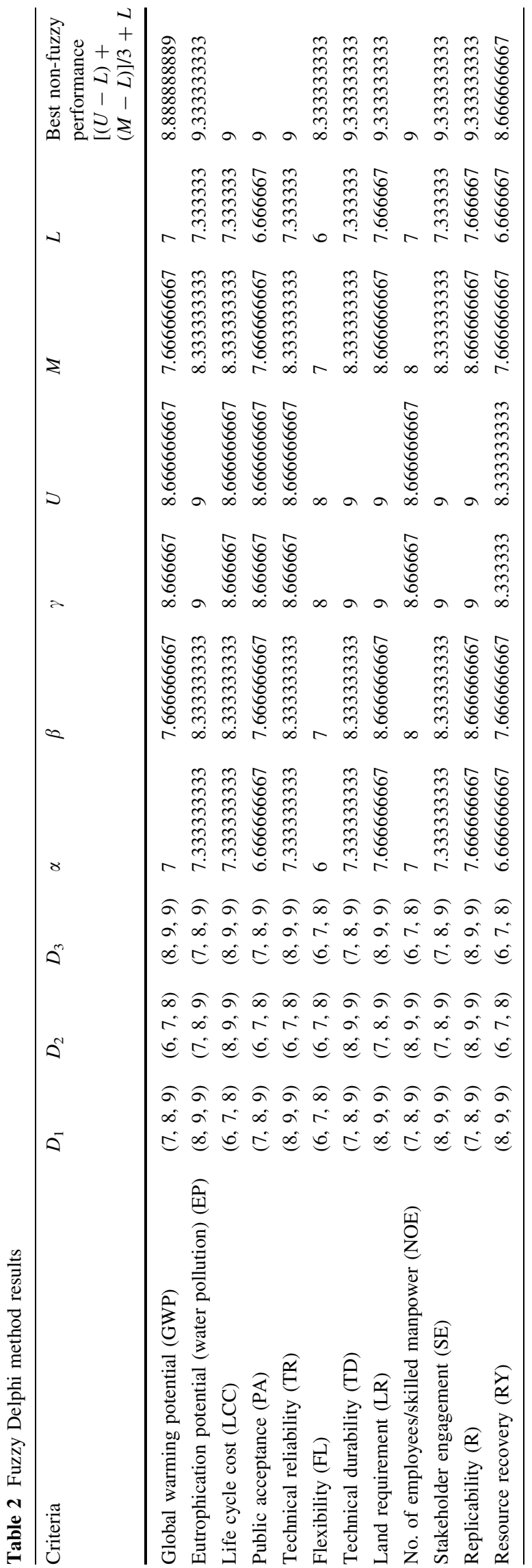

weighing the WWT technology evaluation and selection criteria. To increase the objectivity of results, ten experts were interviewed from the academia, consultancies and the local governing authority.

In this study, the framework of the feasible regions of relative weights was adopted. First, allowing the feasible region to include tolerance deviations of the fuzzy ratios, we defined fuzzy consistency as the existence of relative weights within the region. Second, we devised a maximum/ minimum set ranking method to derive a crisp ranking from the global fuzzy weights.

Using a fuzzy approach, the numerical value of each linguistic term employed in the questionnaire was determined based on the FAHP scale shown in Table 4 (Lin et al. 2006). As it can be observed in Table 4, the solid scale linguistic term has been transformed to equal fuzzy intervals.

The following steps of FAHP proposed by Chang (1996) have been utilised for selecting and ranking the criteria in the multi-period phase. According to the method of Chang's extent analysis, each object is taken, and extent analysis for each goal is performed. Therefore, $m$ extent analysis values for each object can be obtained, with the following signs:

$M_{g^{i}}^{1}, M_{g^{i}}^{2}, \ldots, M_{g^{i}}^{m}, \quad i=1,2, \ldots, n$

where $M_{g^{i}}^{j}(j=1,2, \ldots, m)$ all are triangular fuzzy numbers (TFNs).

The steps of Chang's extent analysis (Chang 1996) are:

1. The value of fuzzy synthetic extent with respect to the $i$ th object is defined as

$$
S_{i}=\sum_{j=1}^{m} M_{g^{i}}^{j} \otimes\left[\sum_{i=1}^{n} \sum_{j=1}^{m} M_{g^{i}}^{j}\right]^{-1}
$$

To obtain $\sum_{j=1}^{m} M_{g^{i}}^{j}$, the fuzzy addition operation of $\mathrm{m}$ extent analysis values for a particular matrix is performed as

$$
\sum_{j=1}^{m} M_{g^{i}}^{j}=\left(\sum_{j=1}^{m} l_{j}, \sum_{j=1}^{m} m_{j}, \sum_{j=1}^{m} u_{j}\right)
$$

and to obtain the fuzzy addition operation of $M_{g^{i}}^{j}(j=$ $1,2, \ldots, m)$ values is performed, such that

$\left[\sum_{i=1}^{n} \sum_{j=1}^{m} M_{g^{i}}^{j}\right]=\left(\sum_{i=1}^{n} l_{i}, \sum_{i=1}^{n} m_{i}, \sum_{i=1}^{n} u_{i}\right)$

and $\left[\sum_{i=1}^{n} \sum_{j=1}^{m} M_{g^{i}}^{j}\right]^{-1}$ can be calculated by the inverse of Eq. (7), as follows: 
Table 3 Evaluation criteria after FDM screening with definitions

\begin{tabular}{lll}
\hline Criteria & Abbr. & Definition \\
\hline Public acceptance & PA & $\begin{array}{l}\text { It refers to the issue of social opposition to the construction of WWT facilities, i.e. socio-cultural } \\
\text { resistance. The identified technology should be accepted socially from socio-economic culture. This } \\
\text { criterion takes into account the issues such as sanitation and odour-related problems to the community } \\
\text { Technical reliability }\end{array} \quad \begin{array}{l}\text { Reliability of the system is defined as the possibility of achieving adequate performance for a specific } \\
\text { period under specific conditions, i.e. the variability of treatment effectiveness under normal and } \\
\text { emergency operation. It represents the WWT technology performance, mechanical reliability (the } \\
\text { probability of mechanical failures) and the impact of failures upon effluent quality. It also concerns } \\
\text { the percentage of the pollutants that are removed from the influent. It represents the robustness of the } \\
\text { system }\end{array}$
\end{tabular}

Eutrophication potential (water pollution)

Life cycle cost

Global warming potential

Flexibility

Technical durability

Land requirement

No. of employees/skilled manpower

Stakeholder engagement

SE

Replicability

Resource recovery
EP It represents the performance of the WWT technology based on the release of organics and nutrients in the effluent, i.e. treated wastewater

LCC It refers to the cost related criterion. In the current study, it is estimated as net present worth (NPW) representing the capital and O\&M costs of the given WWT technology (lakh/MLD-million litres per day). Capital costs include the cost incurred for civil works, electromechanical equipment and the cost of land. O\&M costs include electrical energy and chemicals costs required to operate the plant, labour costs, spare parts and maintenance costs. NPW is quantified using the present worth method in the current study

GWP GWP refers to the carbon footprint of the WWT technology/system. It primarily represents energy consumption, the GHGs emission due to energy consumption, chemical consumption during the operational phase of the WWT systems over their life cycles

FL It refers to the improvement aspects of the WWT technology/system. Often it is required to upgrade an existing WWT system to increase its additional hydraulic and organic load. This criterion attempts to account for the feature of technology to undergo the upgradation easily. The WWT technology should be sufficiently flexible with minimum cost requirement for it

TD Durability is defined as the technological lifetime, which is a significant criterion in the selection of a WWT technology. The technology should have at least 40-50 years of technological life with minimal maintenance and spare part requirements. It also represents the robustness of the system

LR This criterion refers to the land that is required to build the necessary infrastructure for the WWT technology/system. It is expressed in terms of $\mathrm{m}^{2}$ /MLD. This was estimated studying field scale WWT plants

NOE Simplicity is a key factor in the selection of WWT systems. A lack of skilled workers represents a major constraint when decision makers choose to implement a sophisticated treatment system. This criterion further refers to the number of employees dealing with the process of WWT requiring specific skills if any for the O\&M and the management of the technology/system

E It is often neglected when selecting the appropriate WWT technology. The perceptions, preferences and requirements of the public and related stakeholders toward the selection and implementation of a particular technology are important if the technology is to be integrated with local and broader sustainability concerns. The selected WWT technology should promote public participation and make the community responsible for the success of the implementation. This will help to solve several issues related to acceptance, sustainability and preservation of local interests

$\mathrm{R} \quad$ It represents the design, implementation and operational features of the technology. The selected technological solution should be sufficiently familiar and simple so that it can be easily replicated in other places without reliance on specific technical expertise. It also represents the robustness of the system

RY It represents the potential of the WWT technologies to recover energy, nutrients from wastewater and generate effluent with adequate quality to be reused. It can be stimulated by tailoring the technological design. The technology should promote sustainability in the community. Thus, helping in saving scarcely available natural resources

$$
\left[\sum_{i=1}^{n} \sum_{j=1}^{m} M_{g^{i}}^{j}\right]^{-1}=\left(\frac{1}{\sum_{i=1}^{n} u_{i}}, \frac{1}{\sum_{i=1}^{n} m_{i}}, \frac{1}{\sum_{i=1}^{n} l_{i}}\right)
$$

2. As $M_{1}=\left(l_{1}, m_{1}, u_{1}\right)$ and $M_{2}=\left(l_{2}, m_{2}, u_{2}\right)$ are two triangular fuzzy numbers, the degree of possibility of $M_{2}=\left(l_{2}, m_{2}, u_{2}\right) \geq M_{1}=\left(l_{1}, m_{1}, u_{1}\right)$ is defined as 


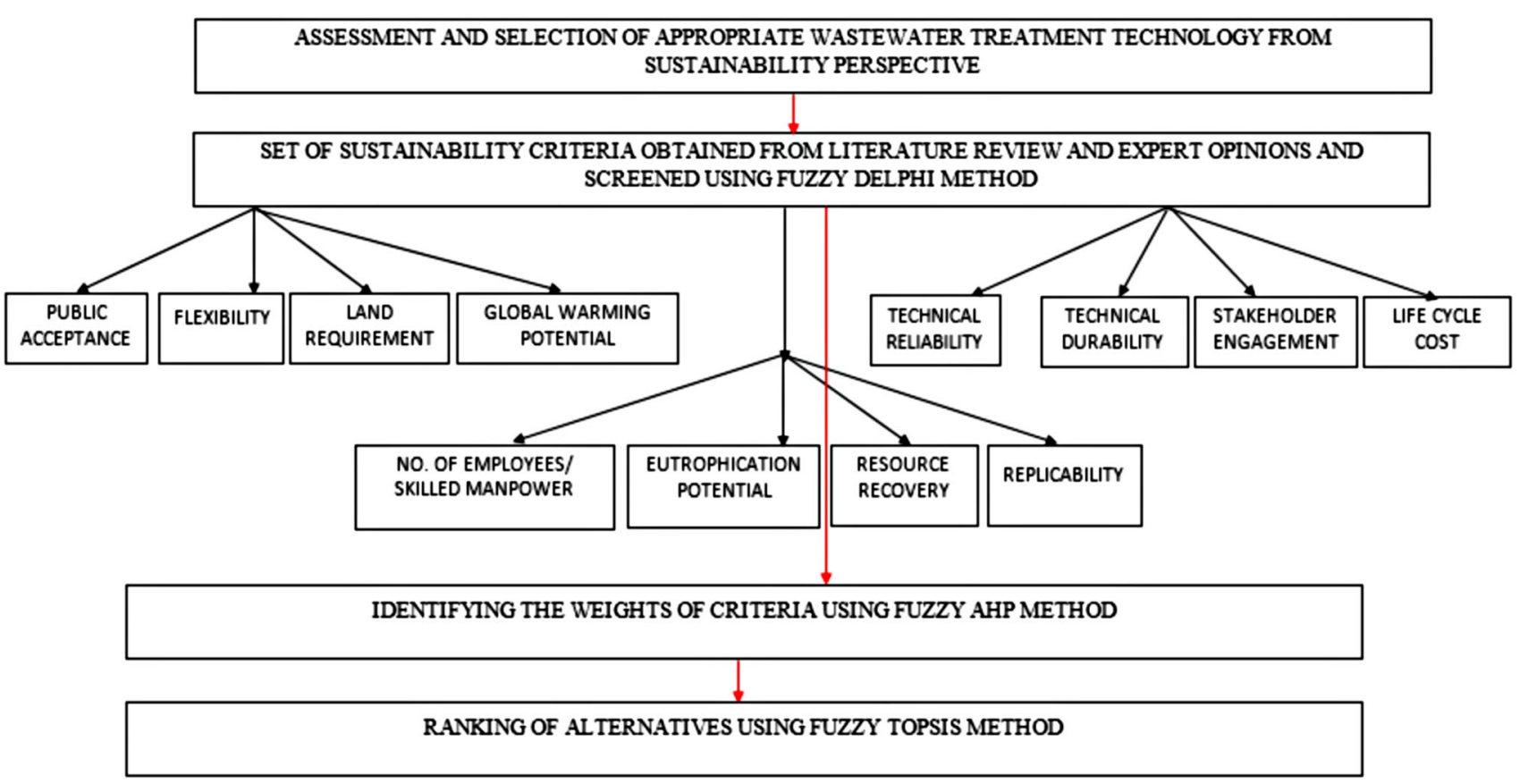

Fig. 3 Criteria selection and technology assessment framework

Table 4 FAHP scale

\begin{tabular}{lll}
\hline \multicolumn{2}{l}{ Fuzzy numbers } & Definition \\
\hline$\tilde{1}$ & $(1,1,1)$ & Equally important \\
$\tilde{2}$ & $(1,2,3)$ & Equally to moderate important \\
$\tilde{3}$ & $(2,3,4)$ & Moderately more important \\
$\tilde{4}$ & $(3,4,5)$ & Moderately and strongly important \\
$\tilde{5}$ & $(4,5,6)$ & More strongly important \\
$\tilde{6}$ & $(5,6,7)$ & Strongly and very strongly important \\
$\tilde{7}$ & $(6,7,8)$ & More very strongly important \\
$\tilde{8}$ & $(7,8,9)$ & Very strongly to extremely important \\
$\tilde{9}$ & $(8,9,9)$ & Extremely more important \\
\hline
\end{tabular}

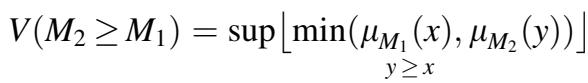

and can be equally expressed as follows:

$V\left(M_{2} \geq M_{1}\right)=\operatorname{hgt}\left(M_{1} \cap M_{2}\right)=\mu_{M_{2}}(d)$

$=\left\{\begin{array}{l}1 \quad \text { if } m_{2} \geq m_{1} \\ 0 \quad \text { if } l_{1} \geq u_{2} \\ \frac{\left(l_{1}-u_{2}\right)}{\left(m_{2}-u_{2}\right)-\left(m_{1}-l_{1}\right)} \text { otherwise }\end{array}\right.$

Figure 4 (Chang 1996) shown below illustrates Eq. (10) where $d$ is the ordinate of the highest intersection point $D$ between $\mu_{M_{1}}$ and $\mu_{M_{2}}$. To compare

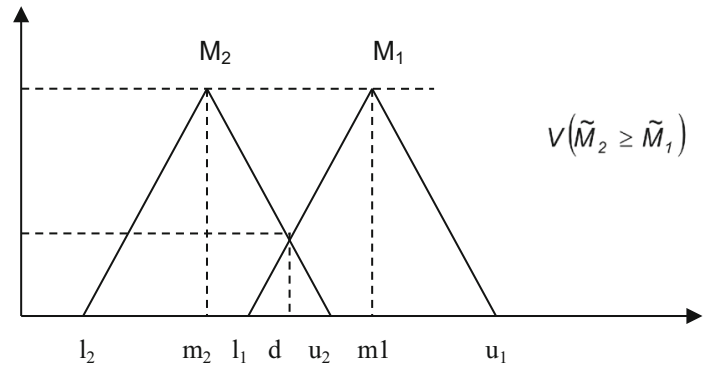

Fig. 4 Intersection between M1 and M2 (Kahraman et al. 2004)

$M_{1}=\left(l_{1}, m_{1}, u_{1}\right)$ and $M_{2}=\left(l_{2}, m_{2}, u_{2}\right)$, we need both the values of $V\left(M_{1} \geq M_{2}\right)$ and $V\left(M_{2} \geq M_{1}\right)$.

3. The degree possibility for a convex fuzzy number to be greater than $k$ convex fuzzy $M_{i}(i=1,2, \ldots, k)$ numbers can be defined by

$$
\begin{aligned}
V\left(M \geq M_{1}, M_{2}, \ldots, M_{k}\right) & =V\left[\left(M \geq M_{1}\right) \text { and }\left(M \geq M_{2}\right)\right. \\
& \text { and } \left.\ldots \text { and }\left(M \geq M_{k}\right)\right] \\
& =\min V\left(M \geq M_{i}\right), \quad i=1,2, \ldots, k
\end{aligned}
$$

Assume that

$d\left(A_{i}\right)=\min V\left(S_{i} \geq S_{k}\right) \quad$ for $\quad k=1,2, \ldots, n ; k \neq i$.

Then the weight vector is given by

$W^{\prime}=\left(d^{\prime}\left(A_{1}\right), d^{\prime}\left(A_{2}\right), \ldots, d^{\prime}\left(A_{n}\right)\right)^{\mathrm{T}}$ 
Table 5 Evaluation criteria weight of experts from different fields

\begin{tabular}{|c|c|c|c|c|c|c|}
\hline Sr. no. & Criteria & $\alpha$ & $\beta$ & $\gamma$ & $\begin{array}{l}\text { Crisp value }=\alpha+4 \beta+\gamma / \\
6\end{array}$ & Ranking \\
\hline 1 & Technical reliability (TR) & 0.278955717 & 0.291321587 & 0.302943986 & 0.291197675 & 1 \\
\hline 2 & Life cycle cost (LCC) & 0.206584225 & 0.212708921 & 0.214213747 & 0.211938942 & 2 \\
\hline 3 & Global warming potential (GWP) & 0.151295629 & 0.15379281 & 0.151471993 & 0.15298981 & 3 \\
\hline 4 & Eutrophication potential (water pollution) (EP) & 0.105616673 & 0.104287027 & 0.102983228 & 0.104291335 & 4 \\
\hline 5 & Land requirement (LR) & 0.08038933 & 0.077098502 & 0.074263758 & 0.077174516 & 5 \\
\hline 6 & Public acceptance (PA) & 0.05098686 & 0.04861736 & 0.049025604 & 0.049080317 & 6 \\
\hline 7 & Flexibility (FL) & 0.043191978 & 0.039468554 & 0.036769203 & 0.039639233 & 7 \\
\hline 8 & Resource recovery $(\mathrm{RY})$ & 0.02805915 & 0.025415112 & 0.024512802 & 0.02570540 & 8 \\
\hline 9 & Technical durability (TD) & 0.022367494 & 0.01956719 & 0.017851146 & 0.01974790 & 9 \\
\hline 10 & Replicability (R) & 0.013874325 & 0.012098972 & 0.011784526 & 0.012342457 & 10 \\
\hline 11 & No. of employees/skilled manpower (NOE) & 0.010488004 & 0.008897834 & 0.008170934 & 0.009041713 & 11 \\
\hline 12 & Stakeholder engagement (SE) & 0.008190616 & 0.006726131 & 0.006009074 & 0.006850702 & 12 \\
\hline
\end{tabular}

where $A_{i}(i=1,2, \ldots, n)$ are the $n$ elements.

4. After normalisation, the normalised weight vectors are

$$
W=\left(d\left(A_{1}\right), d\left(A_{2}\right), \ldots, d\left(A_{n}\right)\right)^{\mathrm{T}}
$$

where $W$ is a non-fuzzy number.

The weights of the evaluation criteria obtained through FAHP are shown in Table 5 below.

\section{Identification of the WWT technologies to be evaluated}

Many WWT technological alternatives have been developed which could potentially be evaluated. There exist some different technical solutions to chosen from. In the current study, the six most widely used WWT technologies in India were evaluated and ranked, viz. an advanced SBR, an advanced MBR, an advanced MBBR, a natural SBT, an FAL and a baseline conventional ASP. Moreover, it should be noted that the six alternatives evaluated in this study can be considered as "classical" technologies to treat wastewater. A short description of the technologies evaluated is given below:

$S B R$ It is based on the activated sludge process. All the operations (fill, react, settle and draw) are achieved in the reactor (batch reactor).

$M B R$ The combination of a membrane process with a conventional suspended growth bioreactor.

$M B B R$ It employs thousands of polyethylene biofilm carriers operating in mixed motion within an aerated WWT basin. It is this high-density population of bacteria that achieves high-rate biodegradation within the system.

$S B T$ It is an eco-friendly technology. The wastewater is treated in the soil-like medium by engaging aerobic bacteria, soil media (weathered rock) containing culture of native microflora and proprietary natural mineral additives.

FAL Facultative aerated lagoons are a type of stabilisation pond, in which wastewater is treated by naturally occurring processes in the influence of solar light, wind, microorganisms and algae. A series of ponds prevents mixing of untreated waste with treated wastewater and allows better control of waste residence time for uniform treatment efficiency.

$A S P$ It is a process for treating wastewaters using air and a biological floc composed of bacteria and protozoa.

\section{Fuzzy-TOPSIS}

The technique for order of preference similar to ideal solution (TOPSIS) was developed for solving the MCDM problems by Hwang and Yoon (1981), based on the concept that the chosen/improved alternatives should be the shortest distance from the positive-ideal solution (PIS) and the farthest from the negative ideal solution (NIS) (Wu et al. 2009). In the current study, after calculating the importance weights and ranking of criteria, a modified FTOPSIS approach has been applied for conducting the ranking process of alternatives (Shih et al. 2007). The rationale of the fuzzy method is to defuzzify imprecise values at the end of the process, not from the beginning (Wang and Elhag 2006). Wang and Elhag (2006) developed an FTOPSIS method based on alpha-level sets to perform defuzzification at the very end of the decision analysis process.

To avoid complicated calculations and to improve the applicability of the proposed approach, the current study utilised the graded mean integration representation method (GMIR) proposed by Chen and Hsieh (2000) to obtain the 
Table 6 Linguistic variables for ratings of alternatives with respect to each criterion

\begin{tabular}{ll}
\hline Very low & $(0,1,2)$ \\
Low & $(2,3,4)$ \\
Medium & $(4,5,6)$ \\
High & $(6,7,8)$ \\
Very high & $(8,9,10)$ \\
\hline
\end{tabular}

final closeness coefficient of each alternative. The formulation of the FTOPSIS is adopted from Jolai et al. (2011). To establish the fuzzy decision matrix, each decision maker employed the linguistic variables shown in Table 6 .

The step-by-step procedure of using the FTOPSIS is listed as follows.

1. Establish the normalised performance matrix.

The purpose of normalising the performance matrix is to unify the unit of matrix entries. Assume that the original performance matrix is

$x=\left(x_{i j}\right) \quad \forall_{i, j}$

where $x_{i j}$ is the performance of alternative $i$ to criterion $j$.

2. Create the weighted normalised performance matrix.

TOPSIS defines the weighted normalised performance matrix as:

$$
\begin{aligned}
V & =\left(V_{i j}\right) \quad \forall_{i, j} \\
V_{i j} & =w_{i j} \times r_{i j} \quad \forall_{i, j}
\end{aligned}
$$

where $w_{j}$ is the weight of criterion $j$.

3. Determine the PIS and NIS.

The ideal solution is computed based on the following equations:

$$
A^{+}=\left\{\left(\max V_{i j} / j \in J\right),\left(\min V_{i j} / j \in J^{\prime}\right), \quad i=1,2, \ldots, m\right\}
$$

$A^{-}=\left\{\left(\min V_{i j} / j\right),\left(\min V_{i j} / j \in J^{\prime}\right), \quad i=1,2, \ldots, m\right\}$

where $j=\{j=1,2, \ldots, n / j$ belongs to benefit criteria $\}$; $j=\{j=1,2, \ldots n / j$ belongs to cost criteria $\}$ :
4. Calculate the distance between PIS and NIS for each alternative:

$$
\begin{aligned}
& S_{i}^{+}=\sqrt{\sum_{j=1}^{n} w_{j} \cdot\left(V_{i j}-V_{j}^{+}\right)^{2}} \quad i=1,2, \ldots, m \\
& S_{i}^{-}=\sqrt{\sum_{j=1}^{n} w_{j} \cdot\left(V_{i j}-V_{j}^{-}\right)^{2}} \quad i=1,2, \ldots, m
\end{aligned}
$$

5. Calculate the relative closeness to the ideal solution of each alternative:

$$
C_{i}^{+}=\frac{S_{i}^{-}}{S_{i}^{+}+S_{i}^{-}} \quad i=1,2, \ldots, m
$$

where $0 \leq c_{i}^{*} \leq 1$ that is, an alternative $i$ is closer to $A_{i}^{*}$ as $C_{i}^{*}$ approaches to 1 .

6. Rank the preference order.

Using the GMIR method, the closeness coefficient of each alternative $\mathrm{A}_{\mathrm{i}}, i=1,2, \ldots, m$ was calculated as follows:

$$
C C_{i}^{+}=\frac{C_{i 1}+4 C_{i 2}+C_{i 3}}{6} \quad i=1,2, \ldots, m
$$

The PIS and NIS computed for each alternative, and the relative closeness values are shown in Table 7.

The closeness coefficient of each alternative was calculated, and on that basis, the final ranking of alternatives was determined, as shown below in Table 8 .

\section{Results and discussion}

In the current study, a hybrid LCA-based fuzzy MCDM

\begin{tabular}{|c|c|c|c|c|c|c|c|c|}
\hline \multicolumn{3}{|l|}{$S i+$} & \multicolumn{3}{|l|}{$S i-$} & \multicolumn{3}{|c|}{$\mathrm{Ci}=\mathrm{Si}-/ \mathrm{Si}+(+) \mathrm{Si}-$} \\
\hline$\alpha$ & $\beta$ & $\gamma$ & $\alpha$ & $B$ & $\gamma$ & $A$ & $\beta$ & $\gamma$ \\
\hline 0.0284 & 0.012144 & 0.006683 & 0.010514 & 0.004744 & 0.002686 & 0.270185 & 0.280906 & 0.286711 \\
\hline 0.025057 & 0.011033 & 0.006193 & 0.025057 & 0.011033 & 0.006193 & 0.5 & 0.5 & 0.5 \\
\hline 0.014646 & 0.006572 & 0.003716 & 0.027876 & 0.012 & 0.006608 & 0.655567 & 0.64613 & 0.640077 \\
\hline 0.035147 & 0.015124 & 0.008361 & 0.003767 & 0.001764 & 0.001009 & 0.096795 & 0.104476 & 0.107651 \\
\hline 0.001088 & 0.000463 & 0.000252 & 0.036507 & 0.016032 & 0.00896 & 0.971054 & 0.971926 & 0.972685 \\
\hline 0.035124 & 0.01951 & 0.013687 & 0.010264 & 0.004459 & 0.002494 & 0.226133 & 0.186038 & 0.15415 \\
\hline
\end{tabular}
methodology was applied for the evaluation and selection of appropriate WWT technology. First, FDM was applied to identify and screen the set of relevant evaluation criteria. The application of FDM produced a set of 12 evaluation
Table 7 Results obtained from FTOPSIS 
Table 8 Ranking of alternatives based on FTOPSIS

\begin{tabular}{llll}
\hline$C C_{i}=C_{i 1}+4 C_{i 2}+C_{i 3 / 6}$ & \multirow{2}{*}{ Ranking } \\
\cline { 1 - 2 } Crisp numbers & Normalized numbers & Alternatives & \\
\hline 0.280086 & 0.104128 & SBT & 4 \\
0.5 & 0.185886 & MBBR & 3 \\
0.646694 & 0.240423 & SBR & 2 \\
0.103725 & 0.038562 & ASP & 6 \\
0.971907 & 0.361328 & MBR & 1 \\
0.187406 & 0.069672 & FAL & 5 \\
\hline
\end{tabular}

criteria eliminating 5 of primary 17 criteria keeping in mind the final objectives and representation issues.

After the screening and finalisation of relevant criteria, FAHP involving pairwise comparisons was applied to calculate relative importance of each criterion. Since linguistic terms were involved, each term was associated with a triangular fuzzy number. The fuzzy evaluation matrix generated was defuzzified using the graded mean integration approach. The consistency among the expert opinions was verified by examining the consistency ratio, which was found to be less than 0.1 , implying good consistency. Next, the fuzzy synthetic extent values $\sim S_{j}$ were computed for the evaluation criteria, and the weight vector was determined. Finally, the normalised weight vector was obtained employing normalisation. Table 5 presents the evaluation criteria weights obtained by applying FAHP. After sequencing, the evaluation criteria have higher significance; thus, decision makers can make timely and more accurate judgments.

In case of the weighing and ranking of the selection criteria for the operational aspect, the experts representing various domains did not exhibit a significant difference in opinion; most of them preferred the TR (0.2911) of the selected technology as an important aspect in the selection of WWT technology as it represents the key element of efficient performance. This can be attributed to the fact that, the selected technology should be technically reliable regarding performance, mechanical reliability with the high efficient removal of the pollutants. Further, the impact of failures upon effluent quality should be low. Life cycle cost $(0.2119)$ was the second most preferred criterion as the cost of particular technology plays a significant role particularly in the case of developing economies like India. More the capital cost and O\&M cost less preferred the WWT technology. The third important criterion according to the experts was GWP (0.1529). Global warming potential represents the carbon footprint of the given WWT technology, i.e. higher the value; higher is the contribution to global warming and related problems which cause ecological imbalances. Hence, the selected WWT technology should have lower GWP. Eutrophication potential (0.1042) obtained the fourth rank in the overall ranking process. EP represents the performance of the WWT technology based on the release of organics and nutrients in the effluent, i.e. how efficient is the technology in removing the organics and nutrients from the influent. Less the EP more is the technology preferred, as it would contribute less to water pollution and produce an effluent of recyclable quality. Land availability is a major concern worldwide. Thus, LR (0.0771) was the fifth most important criterion preferred by the experts, the requirement of large land increases the capital cost involved in implementing the given technology along with an increase in O\&M cost. In addition, the availability of land in an urban setting is almost difficult, and hence less the LR more is the technology preferred. Acceptance of WWT technology by the public or locals is an important factor for the successful implementation of the technology. The selected WWT should not give rise to the "not in my backyard-NIMBY syndrome" as it may hinder the application and success of WWT technology. Thus, PA (0.0490) gained the sixth position in the overall ranking process. This may also help to achieve the triple bottom line. In the priorities obtained for the different criteria, FL (0.0396) gained the seventh place. Flexibility refers to the improvement aspects of the WWT technology/ system and how easily the selected technology can undergo the upgradation. Often it is required to upgrade an existing WWT system to increase its additional hydraulic and organic load. Upgradation of the WWT technology to achieve the desired additional objectives can be very helpful in different scenarios. The flexibility of the treatment system is critical because the changes in the influent hydraulic and organic loadings are unpredictable. Thus, FL is one of the important indicators for analysing the robustness of the technology. The next important criterion to be considered was RY (0.0257) which obtained the eighth rank in the analysis. The ability of the WWT technology to recover nutrients, energy can play a significant role in reducing the carbon footprint of the WWT technology. Also, it helps in saving the limited natural resources. Technical durability (0.0197) was the next important criterion in the ranking process. The selected WWT technology should have a long lifetime with less O\&M. This will add to the sustainability of the WWT technology. The next important criterion preferred by the experts was replicability $(0.01234)$. This particular criterion attempts to account for the design, implementation and operational features of the WWT technology. The selected technological solution should be sufficiently familiar and simple so that it can be easily replicated in other places without reliance on specific technical expertise. It also represents the robustness of the system. The criterion of NOE (0.0090) representing the workforce and specific skills required by them to operate and maintain the selected 
WWT technology obtained the eleventh position in the overall ranking process. This can be justified that the requirement of skillset can be fulfilled by properly training the employees. Stakeholder engagement (0.0068) obtained the last rank. The consideration of SE in the selection process can add to achieve sustainability. Thus, NOE and SE were the least preferred criteria in the WWT technology evaluation and selection process. The result demonstrated that technology-related performance features and economy aspects are the main consideration in the evaluation and selection process. Taking into account the weighting and ranking of the above criteria, it can be concluded that the selection of appropriate WWT technology should promote public participation and make the community responsible for the success of the implementation. This will help to solve several issues related to acceptance, sustainability and preservation of local interests.

Finally, in the third step, the FTOPSIS calculations were executed to determine the appropriate WWT technology option. To do this, experts evaluated the alternatives with respect to each criterion taking into consideration the importance of each criterion. After obtaining the fuzzy weighted decision table, the distance of each alternative from the positive-ideal (FPIS, $\mathrm{A}^{+}$) and negative ideal (FNIS, $\mathrm{A}^{-}$) solutions was calculated using Eqs. 15 and 16. Finally, using the GMIR method, the closeness coefficient (CCi) of each alternative was computed using Eq. 18. Based on CCi values, the ranking of the alternatives was done, and the best alternative was determined.

It is clearly evident from the results of the technology ranking presented in Table 8 that the most preferred WWT technology is MBR (0.3613). The MBR technology requires less land as compared to other technologies. The quality of treated WWT should be recyclable with fewer organic and nutrient loads, which is obtained in MBR, i.e. excellent effluent quality, further from reliability, flexibility and durability MBR offers excellent potential. MBR improves the treatment efficiency by returning the microorganisms sludge and prevents the filamentous fungus. MBR has excellent denitrification efficiency. The benefits of MBR technology over other activated sludge or SBR processes is its ability to operate at average biomass concentrations (MLSS). Furthermore, an MBR system produces less sludge than an SBR system or other technologies considered. The reason for this is the MBR's ability to operate at much longer sludge retention times (SRT). In addition, MBR technology does not require tertiary filtration, polymer addition, or any further treatment processes to provide superior quality effluent. Thus, it is a logical choice as the most appropriate WWT technology. The second most preferred technology under the consideration of relevant criteria is the SBR (0.2404). This can be attributed to the fact that, SBR has high reliability producing good quality effluent. Also, the SBR can undergo modifications that include changes in the aeration system and overall cycle time. Thus, making it an ideal choice in an urban scenario.

MBBR was ranked as the third (0.1858) most preferred option for its potential to produce a good effluent quality, while SBT gained the fourth rank (0.1041). SBT does not require electricity for operation; however, the land requirement is high increasing the capital cost. Also, the SBT requires frequent monitoring of the media making it a rigorous option. The next preferred option was FAL (0.0696). The fact that FAL requires high energy and chemical treatment, rigorous monitoring and operational efforts to keep the treatment stable makes it the less preferred option. Also, the low BOD that is found in domestic wastewaters in FAL treated wastewater makes it the less preferred WWT technology. FAL is also found to be less durable because there are high chances of mechanical failure. The conventional ASP was the least preferred option with the lowest score of 0.0385 . The effluent generated from ASP is of poor quality. Further, the ASP has higher land footprint compared to advanced mechanised systems (MBR, SBR and MBBR) making it a least preferred alternative.

The different aspects of all these technologies, in the form of limitations and advantages, were evaluated with criteria derived from LCA, LCC and other sustainability indicators. The results obtained are in well agreement with previous studies (Metcalf and Eddy 2003); also the WWT efficiencies of advanced mechanised technologies (MBR, SBR and MBBR) are better than the conventional ASP (Kalbar et al. 2013, 2015; Gaouar-Yadi et al. 2014). The mechanised treatment systems (the MBR, the SBR and the MBBR) were found to be more reliable, flexible and durable than the ASP, FAL and the SBT. As advanced mechanised WWT systems have more sophisticated instrumentation, and therefore are more adaptive, which allows them to be more compatible with effluent changes. Mechanised systems are also based on oxygen supplies, which can be precisely predetermined, and a reliable desired effluent quality can be maintained (Kalbar et al. 2012a). Though these advanced mechanised technologies sometimes require higher capital investment and may have higher energy and chemical consumptions based on operating conditions; they are more preferred owing to high effluent reusable quality effluent meeting international standards.

When we compared MBR with SBR and other technologies, the effluent quality of MBR is found to be better than SBR, MBBR and those obtained from conventional technology (Gaouar-Yadi et al. 2014). Also, the reduction in unit process, lower operational requirement, lower cost, high-quality effluent and reduced footprint, makes MBR 
the best choice than other technology available in the market. Though MBR technology has a slightly higher capital cost, the much smaller footprint and the excellent quality effluent produced that can be safely reused for nonpotable purposes offset the negative impacts associated with the technology. Furthermore, by comparison, MBR technology does not require tertiary filtration, polymer addition, or any further treatment processes to provide excellent quality effluent. The evaluation and ranking are consistent with a decision situation where a WWT plant location in the urban area has land availability as a major constraint, and hence advanced mechanised treatments are more preferred than the natural treatment systems (GaouarYadi et al. 2014). However, the natural treatment systems like SBT are preferred whenever land availability is not a concern. The SBT option can be thought of more sustainable option due to the lack of energy requirement for treatment, the potential for community participation for implementation and the ease of operation of the technology and the FAL regarding the potential biogas recovery from the treatment process based on the treatment scenario.

In MCDM problems, data are very often imprecise and fuzzy and quantifying such data is difficult. In the current study, the proposed hybrid method model easily quantifies these types of data. The hybrid method proposed in the present study is found to be superior to other methods since it has the capability of representing vague knowledge taking care of uncertainty. It includes an efficient method to identify and screen the criteria, weigh the criteria and to rank the alternatives. The proposed method has been successfully applied to appropriate WWT technology selection. Further, combining fuzzy logic with AHP and TOPSIS enhances the decision making avoiding ambiguity and uncertainty. The aspect of considering both positive and negative features at the same time makes FTOPSIS most suited method for selecting WWT alternative. Another advantage of FTOPSIS is that it produces more distinct and clear scores for the alternatives and hence it becomes easy for the decision maker to select the best alternative at each preference level.

From WWT plants managers, policy makers and wastewater management agencies perspective, this study involves several implications. While the final solution of the assessment would be very useful for them, it should be noted that the methodological approach followed to support the decision-making process might also be of great usefulness.

\section{Conclusions}

Wastewater treatment technology evaluation and selection is an MCDM process that considers not only scientific analysis and data-mining, but also sustainability factors, political factors and public acceptance with life cycle thinking approach. Thus, the early stage decision-making for WWT coupled with the increasing number of treatment technologies, drivers such as the need for nutrient recovery, energy efficiency, water and sludge reuse presents a formidable challenge. Therefore, constructing a model that intersects the domains of WWT and environmental engineering conveyed the presented results in this study. The assessment carried out in this study focused on sustainability criteria and attributes derived from LCA and LCC thus encompassing economic, environmental and social factors. This leads to having more robust and stable results. The developed framework has demonstrated to be a promising tool to help decision makers in early stage screening and identifying novel treatment concepts. As the decision problem addressed in the current study comprised both qualitative and quantitative information, it was therefore decided to approach the problem using the widely applied fuzzy logic in combination with Delphi, AHP and TOPSIS technique for dealing with complex decision problems.

The current study developed a rational methodology for the inclusion of expert opinions in the decision-making approach based on the FDM, FAHP and FTOPSIS, to help the decision makers and policy analysts for the evaluation and selection process of WWT technologies in a fuzzy environment where the vagueness and subjectivity are handled with linguistic values parameterized by triangular fuzzy numbers. The proposed method enables decision analysts to understand the complete evaluation process better and provide a more accurate, effective, and systematic decision support framework. When compared with existing methods like the AHP and the TOPSIS, the methodology developed in the current study is superior since the fuzzy logic used can take care of incomplete information, vague qualitative data and linguistic variables. Thus, the proposed methodology can be utilised to determine the appropriate WWT technology with an objective and analytical handling of qualitative (linguistic) data. Further, the study incorporated sustainability criteria and attributes derived from LCA and LCC in the evaluation and selection process. The framework developed in the current research for decision-making is most desired for selecting technologies in the context of advanced technological growth; it will help to identify and select sustainable and feasible (appropriate) WWT technologies for efficiently managing wastewaters. The selection and implementation of appropriate WWT technologies will assist developing economies to accomplish the goal of sustainable development.

According to the results, technical reliability and LCC are the major influential criteria that play a major role in the selection of appropriate WWT technology. Then the 
environmental criteria showed significant influence with minor differences. Finally, the last criterion, "stakeholder engagement", indicates the least importance and does not constitute a significant constraint. Further, results illustrated that extensive technologies, MBR and SBR technologies are the most preferred WWT alternatives, due to their high performance and recyclable effluent quality, while conventional ASP was the least preferred option. The results also supported the inclusion of life cycle thinking approach in the decision-making process. One of the significant advantages of the proposed framework is the flexibility, intuitive appeal to policy makers and its ability to check inconsistencies. The FDM, FAHP and FTOPSIS methods serve as powerful complementary tools to determine and rank the evaluation criteria and alternatives more objectively and efficiently. The combination of these techniques provides much well-structured information for experts to understand the problem and present their values and priorities more systematically. Furthermore, in this process, considering the capabilities and constraints together with the specific requirements of the involved sector makes the decision more reliable. The model could be easily adapted to other scenarios by modifying the criteria weights according to the scenario. Therefore, the model could also be utilised in different domains facing a similar problem. The proposed framework is a rationalised process that will be more appropriate in realistic scenarios where multiple stakeholders with local and regional societal priorities are involved in the selection of treatment technology.

In conclusion, the current study provides a simple, robust and flexible methodology for the evaluation and selection of the most appropriate WWT technology. Moreover, the developed methodology takes into account various conflicting issues in the WWT treatment and management process. The study highlights the findings that from the sustainability consideration, the implementation of decentralised WWT systems and the potential of using natural treatment systems need to be increased. Although the current study makes a significant contribution, it is not free from limitations. More real cases should be evaluated to validate the developed methodology. A sensitivity analysis or any other uncertainty modelling technique may be applied enhance the robustness of the method. Future studies should incorporate inputs from other relevant stakeholders such as designers, local communities in the decision-making process, to integrate diverse perspectives for more accurate results. In future, using the above methodology a decision support system can be developed for evaluation and selection of appropriate WWT technology. The application of the above-proposed methodology to other sectors would provide the opportunity for improving the accuracy and comprehensiveness of the study and validating the findings.

Acknowledgements The authors would like to thank the officials of Central Pollution Control Board (Mumbai), Municipal Corporation of Greater Mumbai and academicians for their kind expert opinion and help. On behalf of all authors, the corresponding author states that there is no conflict of interest.

\section{Compliance with ethical standards}

Conflict of interest The present paper is an original work and all the authors declare that they have no conflict of interest.

\section{References}

Anagnostopoulos KP, Gratziou M, Vavatsikos AP (2007) Using the fuzzy analytic hierarchy process for selecting wastewater facilities at prefecture level. Eur Water 19(20):15-24

Asolekar SR, Kalbar PP, Chaturvedi MKM, Maillacheruvu KY (2014) Rejuvenation of rivers and lakes in India: balancing societal priorities with technological possibilities. In: Ahuja S (ed) Comprehensive water quality and purification, 4. Elsevier, USA, pp 181-229

Avramenko Y, Kamami M, Kraslawski A (2010) Fuzzy performance indicators for decision making in selection of wastewater treatment methods. Comput Aided Chem Eng 28(1):127-132

Aydiner C, Sen U, Koseoglu-Imer DY, Dogan EC (2016) Hierarchical prioritization of innovative treatment systems for sustainable dairy wastewater management. J Clean Prod 112(1):4605-4617

Balasubramaniam A, Voulvoulis N (2005) The appropriateness of multicriteria analysis in environmental decision-making problems. Environ Technol 26(9):951-962

Balkema AJ, Preisig HA, Otterpohl R, Lambert AJ, Weijers SR (2001) Developing a model based decision support tool for the identification of sustainable treatment options for domestic wastewater. Water Sci Technol 43(7):265-269

Bani MS, Rashid ZA, Hamid KHK, Harbawi ME, Alias AB, Aris MJ (2009) The development of decision support system for waste management; a review. World Acad Sci Eng Technol 49(1):161-168

Bottero M, Comino E, Riggio V (2011) Application of the analytic hierarchy process and the analytic network process for the assessment of different wastewater treatment systems. Environ Modell Softw 26(10):1211-1224

Bozkurt H, van Loosdrecht MC, Gernaey KV, Sin G (2016) Optimal WWTP process selection for treatment of domestic wastewater-a realistic full-scale retrofitting study. Chem Eng J 286(1):447-458

Chan FTS (2003) Interactive selection model for supplier selection process an AHP. Int J Prod Res 41(15):3549-3579

Chang DY (1996) Applications of the extent analysis method on fuzzy AHP. Eur J Oper Res 95(3):649-655

Chen SH, Hsieh CH (2000) Representation, ranking, distance, and similarity of LR type fuzzy number and application. Aust J Intell Process Syst 6(4):217-229

Cintula P, Fermüller C, Noguera C (2015) Handbook of mathematical fuzzy logic, vol 3. Mathematical Logic and Foundations, Studies in Logic. College publications, London, UK

Curiel-Esparza J, Cuenca-Ruiz MA, Martin-Utrillas M, Canto-Perello J (2014) Selecting a sustainable disinfection technique for wastewater reuse projects. Water 6(9):2732-2747 
De Feo G, Cerrato F, Siano P, Torretta V (2014) Definition of a multicriteria, web-based approach to managing the illegal dumping of solid waste in Italian villages. Environ Technol 35(1):104-114

Dursun M (2016a) Evaluation of wastewater treatment alternatives using fuzzy VIKOR method. J Adv Manag Sci 4(4):333-336

Dursun M (2016b) A fuzzy approach for the assessment of wastewater treatment alternatives. Eng Lett 24(2):1-6

Ehrampoush MH, Miri M, Momtaz SM, Ghaneian MT, Rafati L, Karimi H, Rahimi S (2016) Selecting the optimal process for the removal of reactive red 198 dye from textile wastewater using analytical hierarchy process (AHP). Desalin Water Treatm 57(56):27237-27242

Ekmekçioğlu M, Kaya T, Kahraman C (2010) Fuzzy multicriteria disposal method and site selection for municipal solid waste. Waste Manage 30(8):1729-1736

Felice F, Petrillo A (2013) Multicriteria approach for process modelling in strategic environmental management planning. Int J Simul Process Modell 8(1):6-16

Gao GX, Fan ZP, Zhang Y (2015) MADM method considering attribute aspirations with an application to selection of wastewater treatment technologies. Kybernetes 44(5):739-756

Gaouar-Yadi M, Gaouar-Benyelles N, Benguella B (2014) Comparison between SBR, MBR and activated sludge process efficiency in waste water treatment field. Int J Environ Water 3(5):74-84

Garcia X, Pargament D (2015) Reusing wastewater to cope with water scarcity: economic, social and environmental considerations for decision-making. Resour Conserv Recycl 101:154-166

Garrido-Baserba M, Flores-Alsina X, Rodriguez-Roda I, Poch M (2010) Development of a DSS for the generation of WWTP configuration alternatives. In: Oral Contribution to IEMSs 2010. In: International congress on environmental modelling and software

Garrido-Baserba M, Molinos-Senante M, Abelleira-Pereira JM, FdezGüelfo LA, Poch M, Hernández-Sancho F (2015) Selecting sewage sludge treatment alternatives in modern wastewater treatment plants using environmental decision support systems. J Clean Prod 107:410-419

Gaudreault C, Samson R, Stuart P (2009) Implications of choices and interpretation in LCA for multi-criteria process design: de-inked pulp capacity and cogeneration at a paper mill case study. J Clean Prod 17(17):1535-1546

Gomez-Lopez MD, Bayo J, García-Cascales MS, Angosto JM (2009) Decision support in disinfection technologies for treated wastewater reuse. J Clean Prod 17(16):1504-1511

Hadipour A, Rajaee T, Hadipour V, Seidirad S (2015) Multi-criteria decision-making model for wastewater reuse application: a case study from Iran. Desalin Water Treatm 1:1-8

Hamouda MA, Anderson WB, Huck PM (2009) Decision support systems in water and wastewater treatment process selection and design: a review. Water Sci Technol 60(7):1757-1770

Hsu YL, Lee CH, Kreng VB (2010) The application of fuzzy Delphi method and fuzzy AHP in lubricant regenerative technology selection. Expert Syst Appl 37(1):419-425

$\mathrm{Hu}$ W, Liu G, Tu Y (2016) Wastewater treatment evaluation for enterprises based on fuzzy-AHP comprehensive evaluation: a case study in industrial park in Taihu Basin, China. SpringerPlus 5(1):907-922

Hwang CL, Lin MJ (1987) Group decision making under multiple criteria. Springer, Berlin

Hwang CL, Yoon K (1981) Multiple attribute decision making methods and applications. Springer, Berlin

Ibáñez-Forés V, Bovea MD, Pérez-Belis V (2014) A holistic review of applied methodologies for assessing and selecting the optimal technological alternative from a sustainability perspective. J Clean Prod 70:259-281
Ilangkumaran M, Sasirekha V, Anojkumar L, Sakthivel G, Raja MB, Raj TRS, Kumar SP (2013) Optimization of wastewater treatment technology selection using hybrid MCDM. Manag Environ Qual Int J 24(5):619-641

Ishikawa A, Amagasa M, Shiga T, Tomizawa G, Tatsuta R, Mieno H (1993) The max-min Delphi method and fuzzy Delphi method via fuzzy integration. Fuzzy Sets Syst 55(3):241-253

Jolai F, Yazdian SA, Shahanaghi K, Azari Khojasteh M (2011) Integrating fuzzy TOPSIS and multi-period goal programming for purchasing multiple products from multiple suppliers. J Purchas Supply Manag 17(1):42-53

Kahraman C, Cebeci U, Ruan D (2004) Multi-attribute comparison of catering service companies using fuzzy AHP: the case of Turkey. Int J Prod Econ 87(2):171-184

Kalbar PP, Karmakar S, Asolekar SR (2012a) Selection of an appropriate wastewater treatment technology: a scenario-based multiple-attribute decision-making approach. J Environ Manage 113(1):158-169

Kalbar PP, Karmakar S, Asolekar SR (2012b) Technology assessment for wastewater treatment using multiple-attribute decision-making. Technol Soc 34(4):295-302

Kalbar PP, Karmakar S, Asolekar SR (2013) The influence of expert opinions on the selection of wastewater treatment alternatives: a group decision-making approach. $\mathrm{J}$ Environ Manage 128(1):844-851

Kalbar PP, Karmakar S, Asolekar SR (2015) Selection of wastewater treatment alternative: significance of choosing MADM method. Environ Eng Manag J 14(5):1011-1020

Kalbar PP, Karmakar S, Asolekar SR (2016) Life cycle-based decision support tool for selection of wastewater treatment alternatives. J Clean Prod 117(1):64-72

Kardaras DK, Karakostas B, Mamakou XJ (2013) Content presentation personalisation and media adaptation in tourism web sites using fuzzy Delphi method and fuzzy cognitive maps. Expert Syst Appl 40(6):2331-2342

Karimi AR, Mehrdadi N, Hashemian SJ, Bidhendi GN, Moghaddam RT (2011) Selection of wastewater treatment process based on the analytical hierarchy process and fuzzy analytical hierarchy process methods. Int J Environ Sci Technol 8(2):267-280

Khoram MR, Shariat M, Azar A, Moharamnejad N, Mahjub H (2007) Prioritizing the strategies and method of treated wastewater reusing by fuzzy analytic hierarchy process: a case study. Int $\mathrm{J}$ Agric Biol 9(2):319-323

Klir GJ, Yuan B (1995) Fuzzy sets and fuzzy logic-theory and application. Prentice-Hall Inc, New Jersey

Laarhoven PJM, Pedrycz W (1983) A fuzzy extension of Sati's priority theory. Fuzzy Sets Syst 11:229-241

Li W, Guangwen M (1990) Application of multi objective programming with analytical hierarchy process to river water management. Hydrol Basis Water Resour Manag Proc Beijing Symp 197:193-198

Lin CT, Chiu H, Chu PY (2006) Agility index in the supply chain. Int J Prod Econ 100(2):285-299

Liu HC, Liu L, Liu N, Mao LX (2012) Risk evaluation in failure mode and effects analysis with extended VIKOR method under fuzzy environment. Expert Syst Appl 39(17):12926-12934

McCarty PL, Bae J, Kim J (2011) Domestic wastewater treatment as a net energy producer-can this be achieved? Environ Sci Technol 45(17):7100-7106

Metcalf \& Eddy (2003) In: Tchobanoglous G, Burton FL (eds) Wastewater engineering: treatment, disposal, and reuse, 4th edn. McGraw Hill Inc. International/Metcalf and Eddy, Inc, New York

Mikhailov L (2003) Deriving priorities from fuzzy pair-wise comparison judgments. Fuzzy Sets Syst 134(3):365-385 
Molinos-Senante M, Gómez T, Garrido-Baserba M, Caballero R, Sala-Garrido R (2014) Assessing the sustainability of small wastewater treatment systems: a composite indicator approach. Sci Total Environ 497:607-617

Molinos-Senante M, Gómez T, Caballero R, Hernández-Sancho F, Sala-Garrido R (2015) Assessment of wastewater treatment alternatives for small communities: an analytic network process approach. Sci Total Environ 532:676-687

Molinos-Senante M, Gémar G, Gómez T, Caballero R, Sala-Garrido $\mathrm{R}$ (2016) Eco-efficiency assessment of wastewater treatment plants using a weighted Russell directional distance model. J Clean Prod 137(1):1066-1075

Murray TJ, Pipino LL, van Gigch JP (1985) A pilot study of fuzzy set modification of Delphi. Human Syst Manag 5(1):76-80

Noorderhaben N (1995) Strategic decision making. Addison-Wesley, UK

Ouyang X, Guo F, Shan D, Yu H, Wang J (2015) Development of the integrated fuzzy analytical hierarchy process with multidimensional scaling in selection of natural wastewater treatment alternatives. Ecol Eng 74:438-447

Pilavachi PA, Stephanidis D, Pappas VA, Afgan NH (2009) Multicriteria evaluation of hydrogen and natural gas fuelled power plant technologies. Appl Therm Eng 29:2228-2234

Pochampally KK, Gupta SM, Kamarthi SV (2003) Evaluation of production facilities in a closed-loop supply chain: a fuzzy TOPSIS approach. In: III SPIE international conference on environmentally conscious manufacturing. Providence, Rhode Island

Pophali GR, Chelani AB, Dhodapkar RS (2011) Optimal selection of full scale tannery effluent treatment alternative using integrated AHP and GRA approach. Expert Syst Appl 38(9):10889-10895

Prasad AD, Tembhurkar AR (2013) Decision making software for effective selection of treatment train alternative for wastewater using analytical hierarchy process. J Environ Sci Eng 55(4):397-408

Rawal N, Duggal SK (2016) Life cycle costing assessment-based approach for selection of wastewater treatment units. Natl Acad Sci Lett 39:1-5
Reardon R, Davel J, Baune D, McDonald S, Appleton R, Gillette R (2013) Wastewater treatment plants of the future: current trends shape future plans. Florida Water Resour J 10(1):8-14

Sadr S, Onder T, Saroj DP, Ouki S (2013) Appraisal of membrane processes for technology selection in centralized wastewater reuse scenarios. Sustain Environ Res 23(2):69-78

Shih HS, Shyur HJ, Lee ES (2007) An extension of TOPSIS for group decision making. Math Comput Modell 45(7):801-813

Tan RR, Aviso KB, Huelgas AP, Promentilla MAB (2014) Fuzzy AHP approach to selection problems in process engineering involving quantitative and qualitative aspects. Process Saf Environ Prot 92(5):467-475

Tang SL, Ellis KV (1994) Wastewater treatment optimization model for developing world. II: model testing. J Environ Eng 120(3):610-624

Tecle A, Duckstein L (1990) Multicriterion selection of wastewater management alternatives. J Water Resour Plann Manag 116(6):840-841

Tecle A, Fogel M, Duckstein L (1988) Multicriterion selection of wastewater management alternatives. J Water Resour Plann Manag 114(4):383-398

Wang YM, Elhag T (2006) Fuzzy TOPSIS method based on alpha level sets with an application to bridge risk assessment. Expert Syst Appl 31(2):309-319

Wang JJ, Jing YY, Zhang CF, Zhao JH (2009) Review on multicriteria decision analysis aid in sustainable energy decisionmaking. Renew Sustain Energy Rev 13(9):2263-2278

Wu HY, Tzeng GH, Chen YH (2009) A fuzzy MCDM approach for evaluating banking performance based on balanced scorecard. Expert Syst Appl 36(6):10135-10147

Zadeh LA (1965) Fuzzy sets. Inf Control 8(3):338-353

Zayed T, Chen Z, Qasem A (2015) Infrastructure performance rating models for wastewater treatment plants. Struct Infrastruct Eng 11(5):668-682

Zeng G, Jiang R, Huang G, Xu M, Li J (2007) Optimization of wastewater treatment alternative selection by hierarchy grey relational analysis. J Environ Manage 82(2):250-259 